\title{
Fuzzy Logic Controller for Washing Machine with Five input \& Three output
}

\author{
Tarik Ahmed \\ Student, Department of Electrical \& Electronics Engineering, Al-Falah University \\ Faridabad, Haryana, India \\ Aziz Ahmad \\ Professor, Department of Electrical \& Electronic Engineering, Al-Falah University \\ Faridabad, Haryana, India
}

Ashu Toki

Faculty, Department of Electronics \& Communication Engineering, Baba Saheb Ambedkar Polytechnic college

Delhi,India

\begin{abstract}
Now a day, intelligent control of home appliances has rapid market penetration. In this paper, we have proposed the fuzzy logic controller having five inputs to give correct wash, rinse and spin time of fully automatic machine .The basic purpose is to save a lot of time, electricity and water for washing the cloth. The proposed FLC is simulated using Fuzzy Logic Toolbox of MATLAB. The result is used to calculate the wash time, rinse time and spin time for different type of input conditions.
\end{abstract}

Keywords - FIS Editor, Fuzzy Logic Controller, MATLAB, Rule Viewer, Surface Viewer.

\section{INTRODUCTION}

Washing machines are common household appliances in India but washing machine that efficiently controls the wash time is vital. Conventional, proportional, integral and differential [PID] controllers have proven to be less capable so fuzzy logic enables designers to control complex systems more effectively than traditional approaches.

Electronic appliances manufacturer companies are working on the sensor based fully-automatic washing machines which can sense wash load, water level, type of fabric, type of dirt and dirtiness of clothes to decide the ideal time for washing, number of rinses and spin period as per the information picked by the sensor systems to the machine. The success of sensor based washing machine depends upon the availability of reliable and durable sensors. The presently available sensors for washing machine in the market are load sensor, turbidity sensor, temperature sensor and optical sensor.

The users of washing machines have been facing the problem of selecting the length of wash time based on the type of clothes, type of dirt, dirtiness of clothes and amount of clothes. Most of the people find it very difficult to decide that which cloth needs what amount of washing time. To overcome these problems fully-automatic washing machines based on fuzzy logic offers the advantage of performance, simplicity and less cost.

In this paper, we have introduced five input variables and three output fuzzy logic controller to get correct wash time, rinse time and spin time. Fuzzy logic toolbox in MATLAB is used for FLC simulation. The results so obtained from the fuzzy logic toolbox for the proposed system are compared with the available fuzzy based washing machine.

\section{LITERATURE REVIEW}

Fuzzy Logic: In 1965 the concept of fuzzy logic was first conceived by Professor Lotfi A. Zadeh University of California, Berkeley [1]. Fuzzy logic is powerful design philosophy for describing and developing control systems which provides simple and intuitive method for design engineers to implement complex systems. [2] Fuzzy logic systems allows for an input to exist with varying degree at more than one state at a time and hence allows the engineers to describe the system in more than natural terms. [3]

Fuzzy Logic Controller and Its Applications: Fuzzy Controllers, [4] as contrary to classical controllers are capable of utilizing knowledge elicited from human decisions or human operators. Fuzzy Logic Controller for Gas Heater was designed using behavioral modeling and then these modules are connected via structural VHDL to control "Valve Angle." [5] 
The fuzzy logic controller for Liquid Level Control was designed using MATLAB for controlling "Valve" and compared with the PID controller. The comparison results show that fuzzy logic controller significantly reduced overshoots and steady state error. [6]

In 2007, the Fuzzy Inference is used for determining Wash time. In this design MF used was triangular; the inputs of the Fuzzy Controller were Change of Turbidity and Turbidity, the output was Washing Time. [7] In 2009, Pritesh Lohani, proposed "An improved Controller Microchip for Washing Machine" that comprises of three LIs i.e. Types of Dirt, Dirtiness of Clothes and Mass of Clothes and the LO Wash Time with 25 rules. [8] In 2011, Manish Aggarwal, proposed the Fuzzy Logic Control for Washing Machine having two inputs Type of Dirt and different Degree of Dirt and the output was Wash Time with the inference engine which provides 9 rules for the FLC. The input-output relation is determined by using Fuzzy Interface Unit. [9]

With the above information, a new FLC for Washing Machine is proposed with five inputs and three output variables and 216 rules.

\section{PROPOSED DESIGN}

The proposed Fuzzy Logic Controller for washing machine consists of five Linguistic Inputs i.e.

- $\quad$ Type of dirt

- Amount of dirt

- Types of clothes

- Amount of clothes

- Temperature

The sensors for all these LIs are also available in the market. All the above LIs control the three LO i.e.

- Wash Time

- $\quad$ Rinse Period

- $\quad$ Spin Period

The proposed Fuzzy Logic Controller inference engine is designed using 216 rules for Wash Time, 216 rules for rinse period and 25 rules for Spin Period. The rules formed in this research are derived from the common sense and purely based on experience from a typical home use. Every Linguistic inputs and outputs has a set of membership functions. The MF used for all LIs and LOs is triangular MF. The X-axis of all the MF graphs represents the LI values which are obtained from the sensors and it ranges from 0 to 1 up to first whereas the Y-axis of all MF graph denotes the degree of membership function which ranges from 0 to 1 .

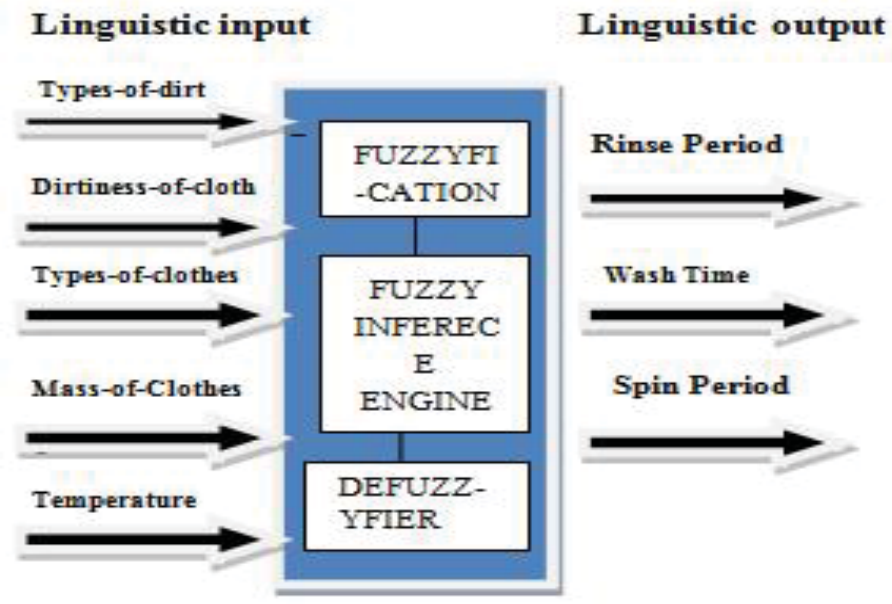

Figure. 1 FLC for Washing Machine

Figure 1 shows the basic approach to the proposed FLC. Fuzzy Logic Controller for Washing Machine consists of mainly three blocks i.e. Fuzzifier, Fuzzy Rule selector and defuzzifier.

Fuzzification: To deal with the details of fuzzy logic controller, the values for the input and output variables are determined in advanced. There is membership function which is used to map the crisp input values to the fuzzy values and after that suitable operation is applied on them. The process which converts crisp value in fuzzy value is known as fuzzification. 
Fuzzy Rule Select: The decisions made by fuzzy logic controller are derived from the rules known as fuzzy rules. The 216 rules are formed using LIs for LO Wash time is discussed in terms of IF and THEN statements below:

Rule 1: IF (types of clothes is cotton) and (type of dirt is greasy) and (dirtiness of clothes is large) and (mass of clothes is heavy) and (temperature is hot) THEN wash time is long)

Rule 2: IF (types of clothes are cotton) and (type of dirt is greasy) and (dirtiness of clothes is medium) and (mass of clothes is medium) and (temperature is moderate) THEN (wash time is long).

Rule 216: IF (types of clothes are woolen) and (type of dirt is not greasy) and (dirtiness of clothes is small) and (mass of clothes is light) and (temperature is cold) THEN (wash time is very short).

All the above discussed rules combined together using MIN-MAX fuzzy inference technique.

Similarly 216 rules for the rinse period can be read using IF and THEN statements:

Rule 1: IF (types of clothe is cotton) and (type of dirt is greasy) and (dirtiness of clothes is large) and (mass of clothes is heavy) and (temperature is hot) then (rinse period is low).

Rule 2: IF (types of clothe is cotton) and (type of dirt is greasy) and (dirtiness of clothes is medium) and (mass of clothes is medium) and (temperature is moderate) then (rinse period is medium).

Rule 216: IF (types of clothe is woolen) and (type of dirt is not greasy) and (dirtiness of clothes is small) and (mass of clothes is light) and (temperature is cold) THEN (rinse period is very low).

All the above discussed rules combined together using MIN-MAX fuzzy inference technique.

Similarly 25 rules for the spin period can be read using IF and THEN statements:

Rule 1: IF (types of cloth are cotton) and (mass of clothes is heavy) and (temperature is hot) and (atmospheric pressure is low) THEN (spin period is low).

Rule 2: IF (types of cloth are cotton) and (mass of clothes is medium) and (temperature is moderate) and (atmospheric pressure is medium) THEN (spin period is medium).

Rule 25: IF (types of clothes are woolen) and (mass of clothes is light) and (temperature is cold) and (atmospheric pressure is high) THEN (wash time is very high).

Defuzzification: The result obtained from fuzzy inference technique is then processed to produce a quantifiable result i.e. the total time it takes to wash the clothes (Wash Time), it takes to rinse the clothes (Rinse Period) and finally to spin the clothes (Spin Period). Defuzzification process is used to interpret the membership degrees of the fuzzy sets in some specific real value (i.e. in crisp value opposite to that Fuzzification do). Centroid method is used for defuzzification.

\section{SIMULATION AND RESULTS}

Fuzzy Logic Toolbox is used to create and edit fuzzy inference systems within the framework of MATLAB. Using command line functions the results for different LO's shown below.

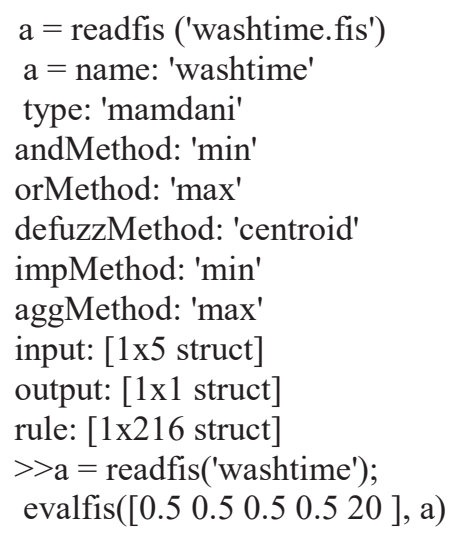


ans $=12.6650$

$>>\mathrm{a}=$ readfis('washtime');

evalfis $([0.635 .245 .5 .520]$, a)

ans $=22.0962$

plotfis(a),

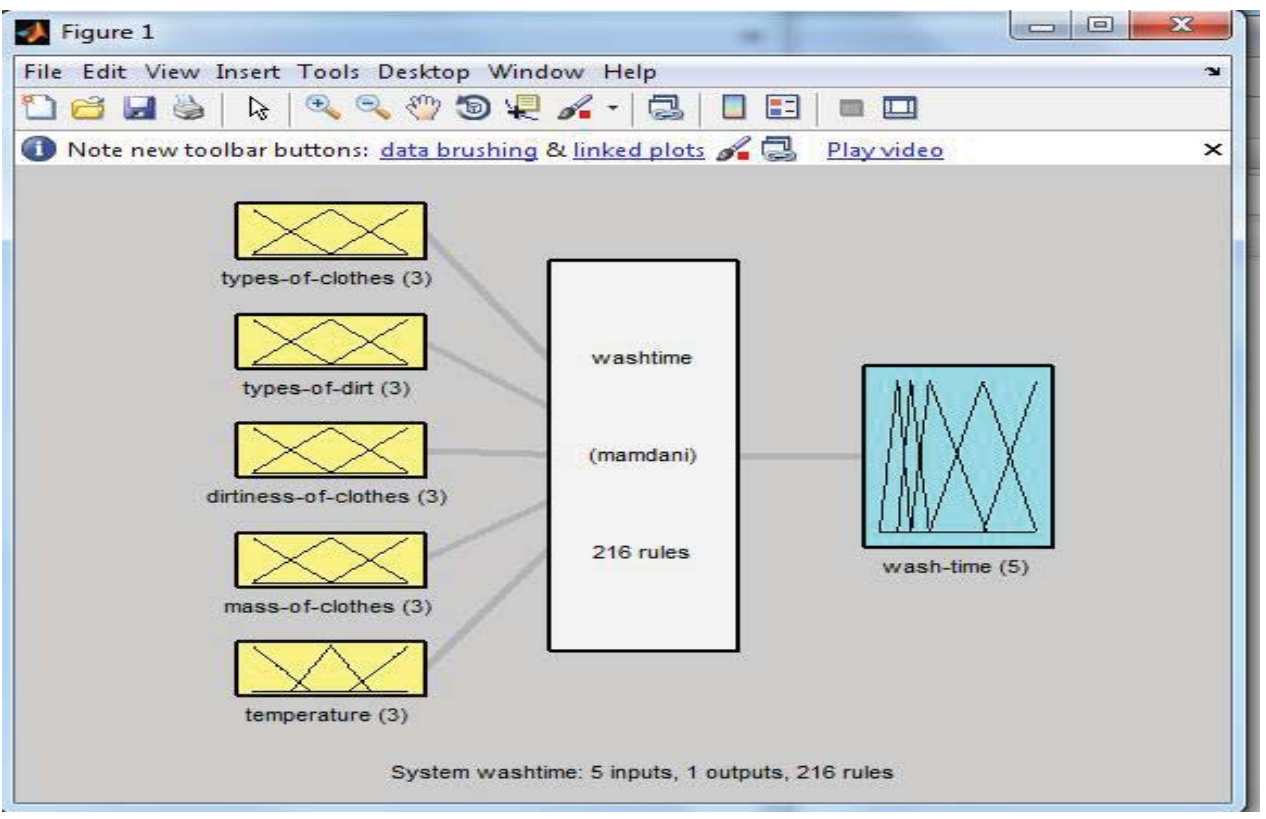

Figure. 2 Fuzzy Logic Controller for Wash Time

Using following commands we obtain the MFs for different LIs and LOs plotmf(a,'input',2)

plotmf(a,'input',3)

plotmf(a,'output',1)

$>$ gensurf(a)

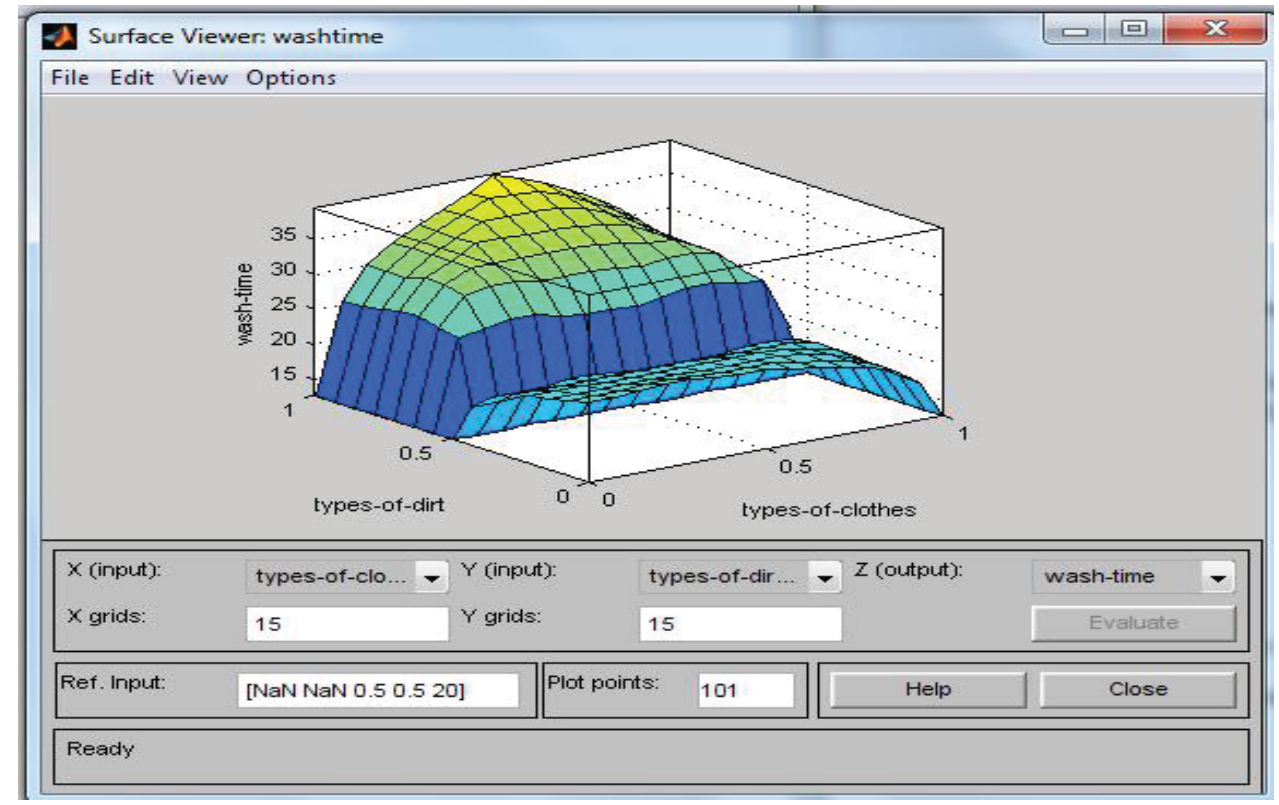

Figure.3 Surface Viewer for Wash time 
>>ruleview(a)

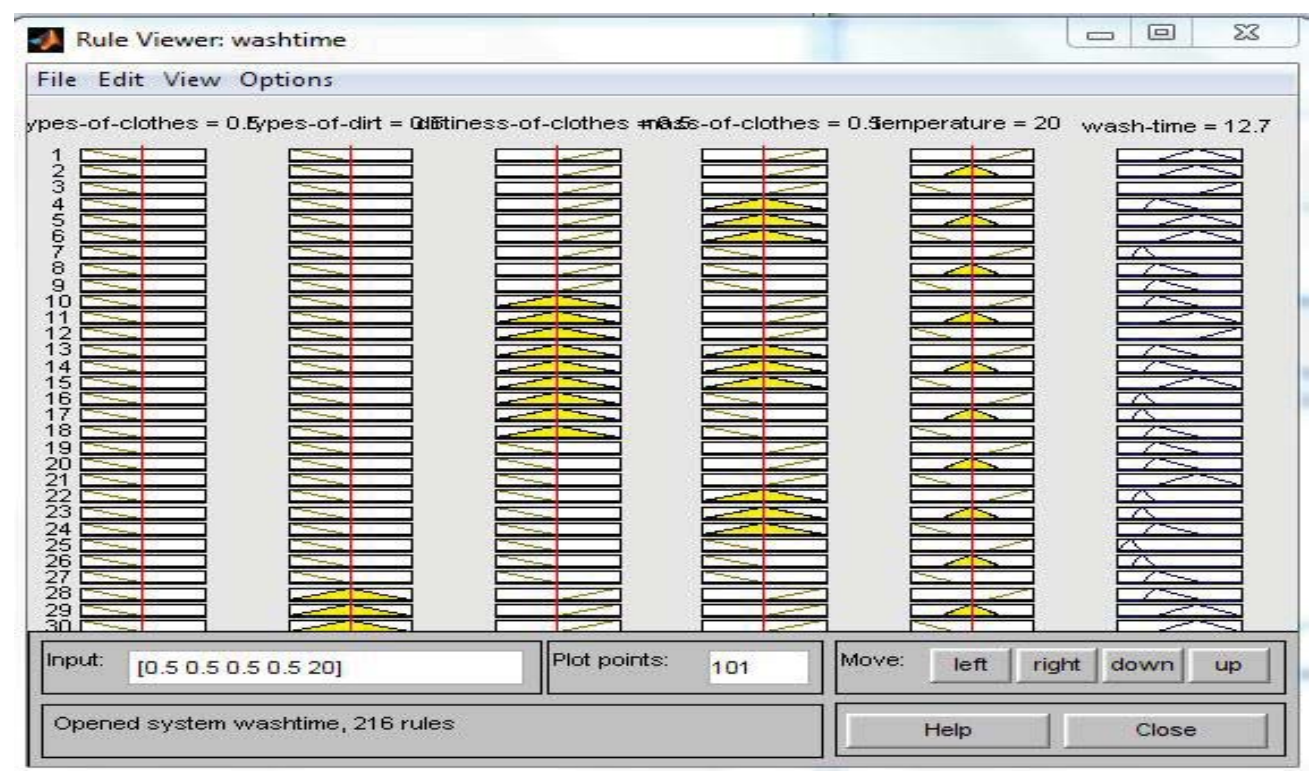

Figure. 4 Rule Viewer For LO Wash Time

Evaluation of Real Values on the Bases of Rules for the Rinse Period-

$\mathrm{a}=$ readfis('rinseperiod.fis')

$\mathrm{a}=$ name: 'rinseperiod'

type: 'mamdani'

and Method: 'min'

or Method: 'max'

defuzz Method: 'centroid'

imp Method: 'min'

agg Method: 'max'

input: $[1 \times 5$ struct $]$

output: [1x1 struct]

rule: [1x216 struct]

$>>\mathrm{a}=$ readfis('rinseperiod');

evalfis([ $\left[\begin{array}{lllll}0.5 & 0.5 & 0.5 & 0.5 & 20\end{array}\right]$, a)

ans $=4.0000$

$>>\mathrm{a}=$ readfis('rinseperiod');

evalfis([0.745 0.654 .325 .566 29], a)

ans $=7.8734$

>>ruleview(a)

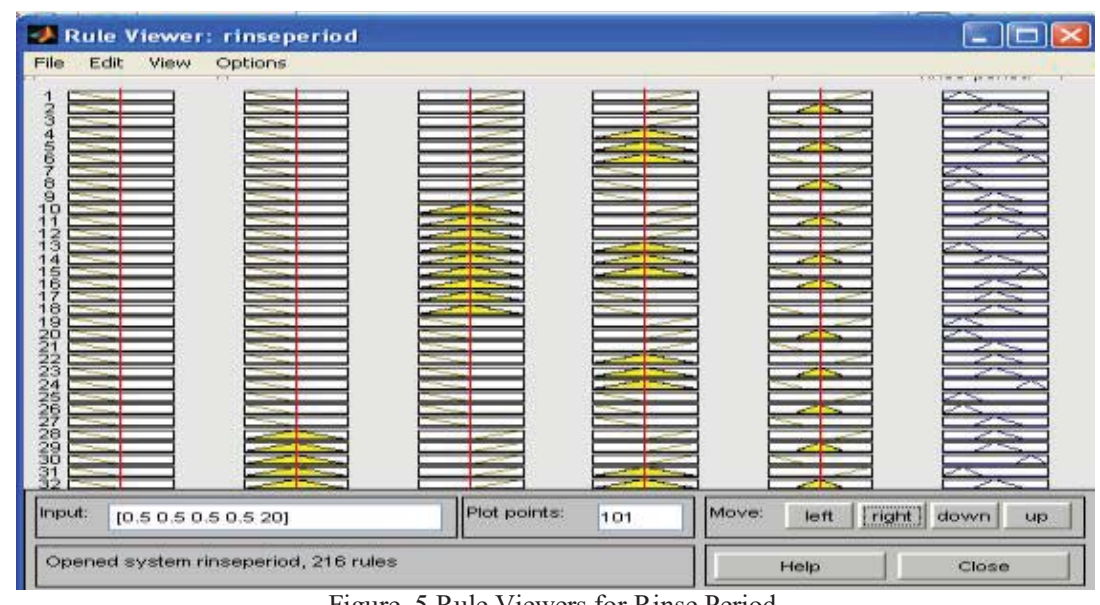

Figure. 5 Rule Viewers for Rinse Period 
$>$ surfview(a)

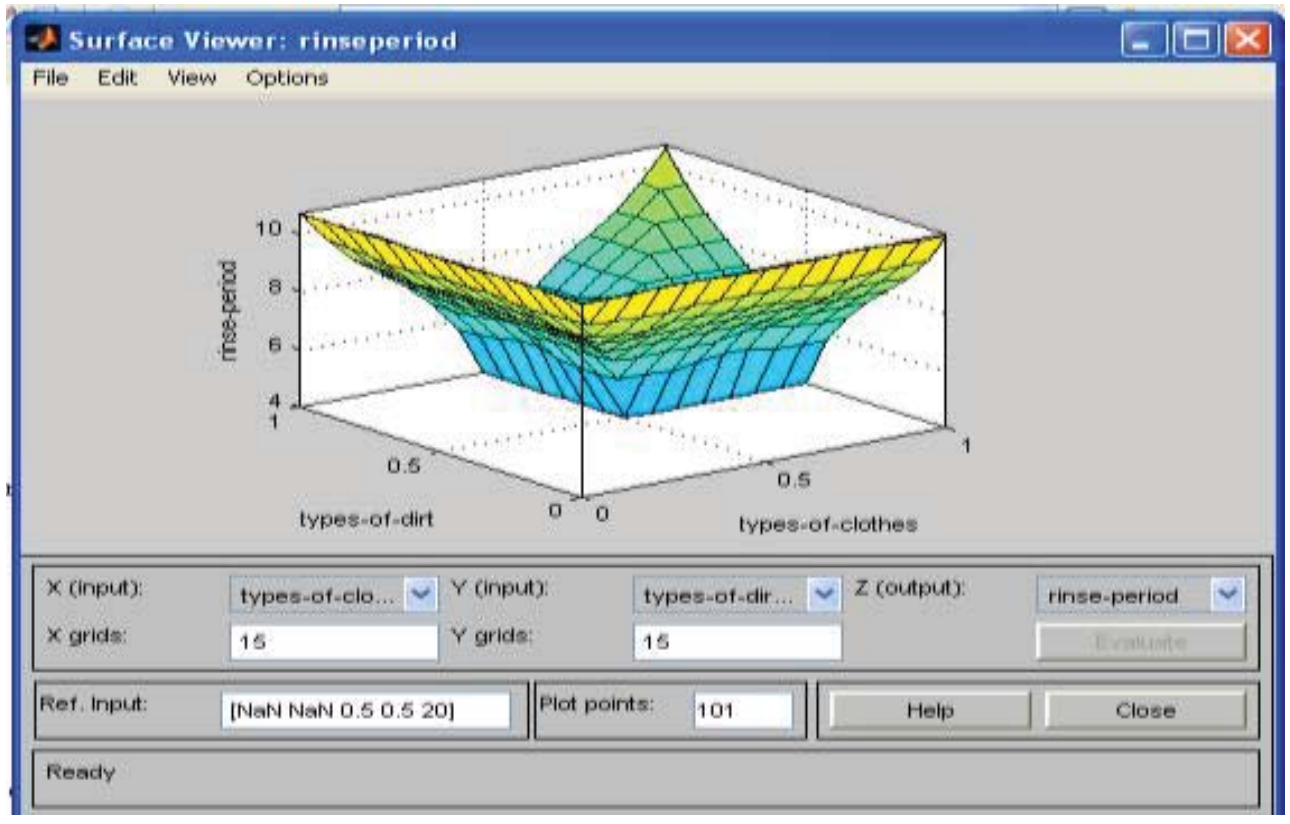

Figure. 6 Surface Viewers for Rinse Period

$>>$ plotfis $(a)$

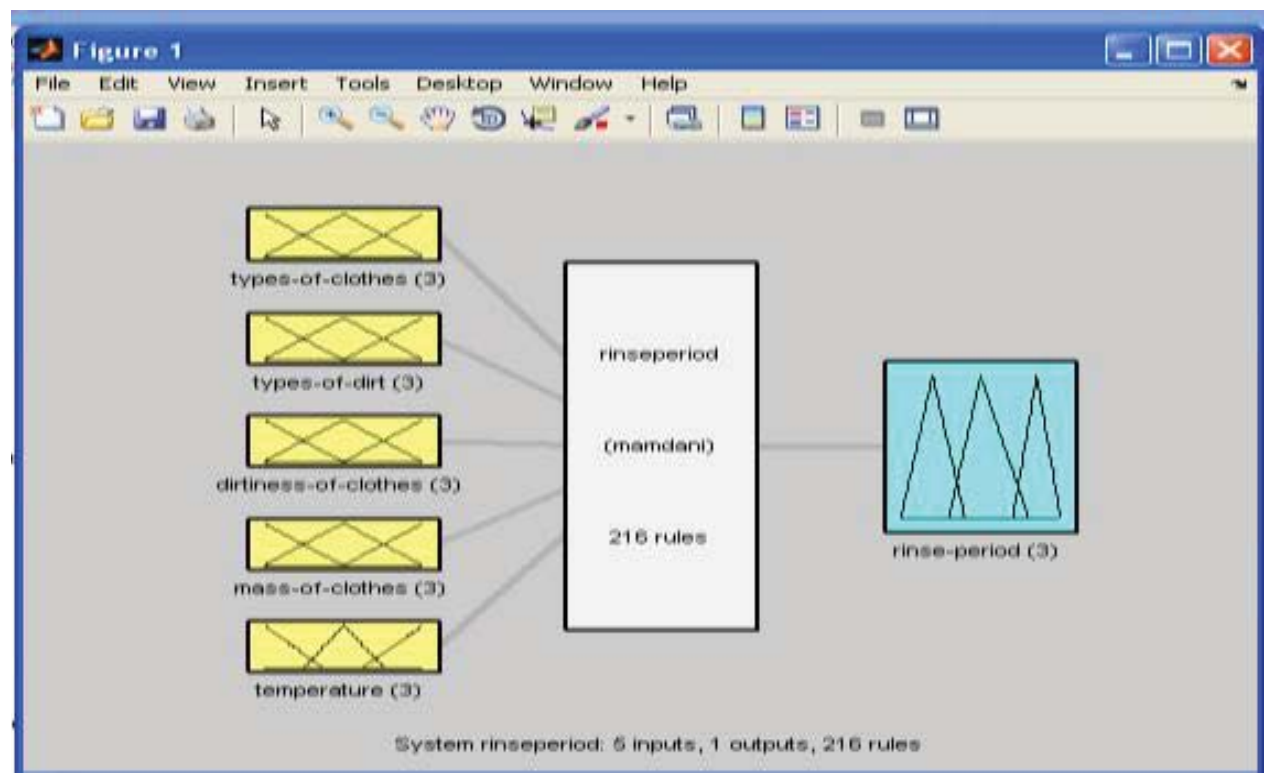

Figure. 7 Fuzzy Logic Controller for LO rinse period

Evaluation Of Real Values On The Bases Of Rules For The Spin Period-

$\mathrm{a}=$ readfis('spinperiod.fis')

$\mathrm{a}=$ name: 'spinperiod'

type: 'mamdani'

and Method: 'min'

or Method: 'max'

defuzz Method: 'centroid'

imp Method: 'min'

agg Method: 'max' 

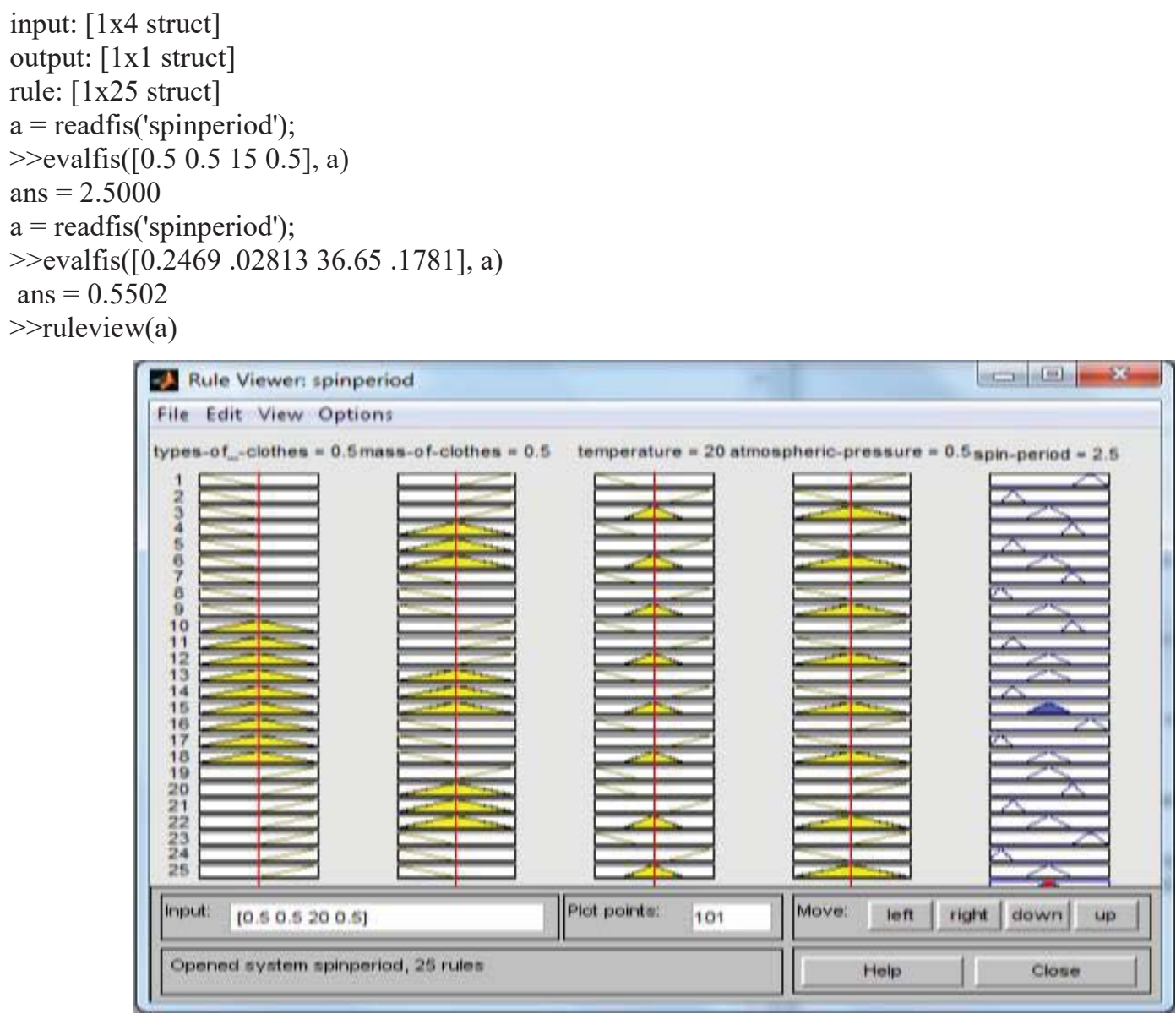

$>>$ plotfis(a)

Figure. 8 Rule Viewer for Spin Period

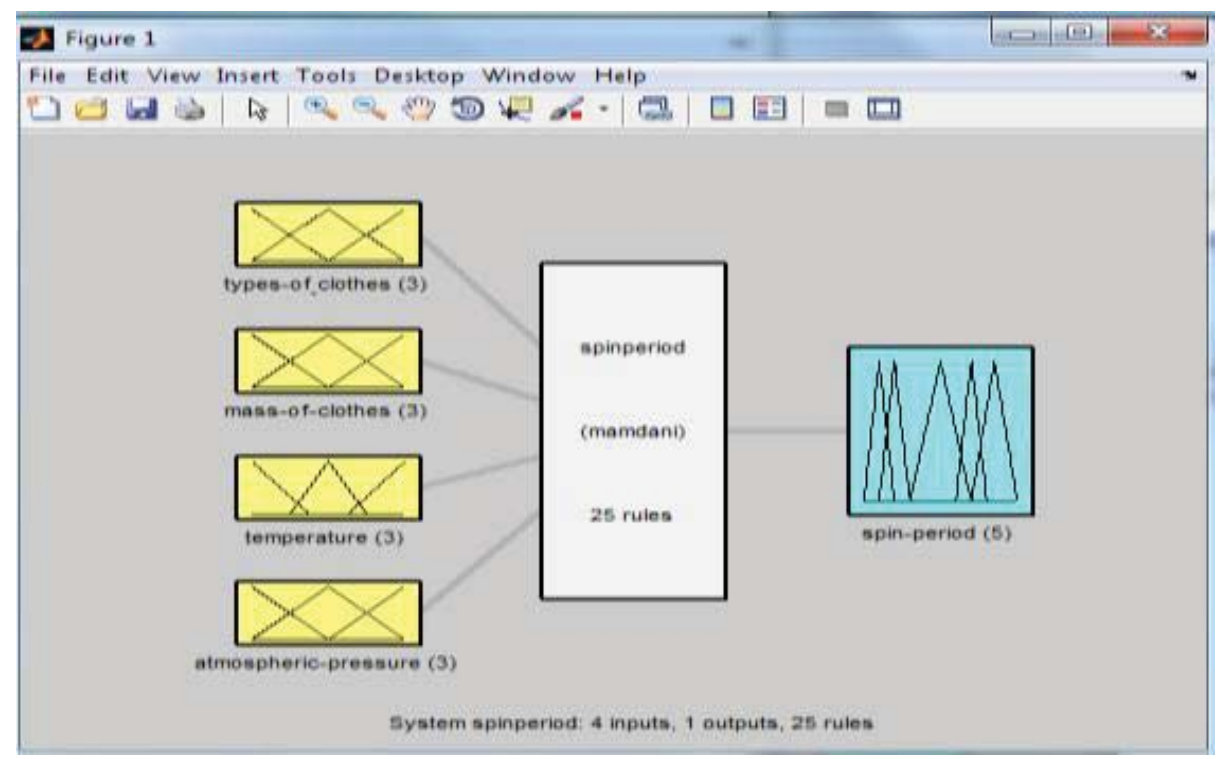

Figure. 9 Fuzzy Logic Controller for Spin period 
$>>$ surfview(a)

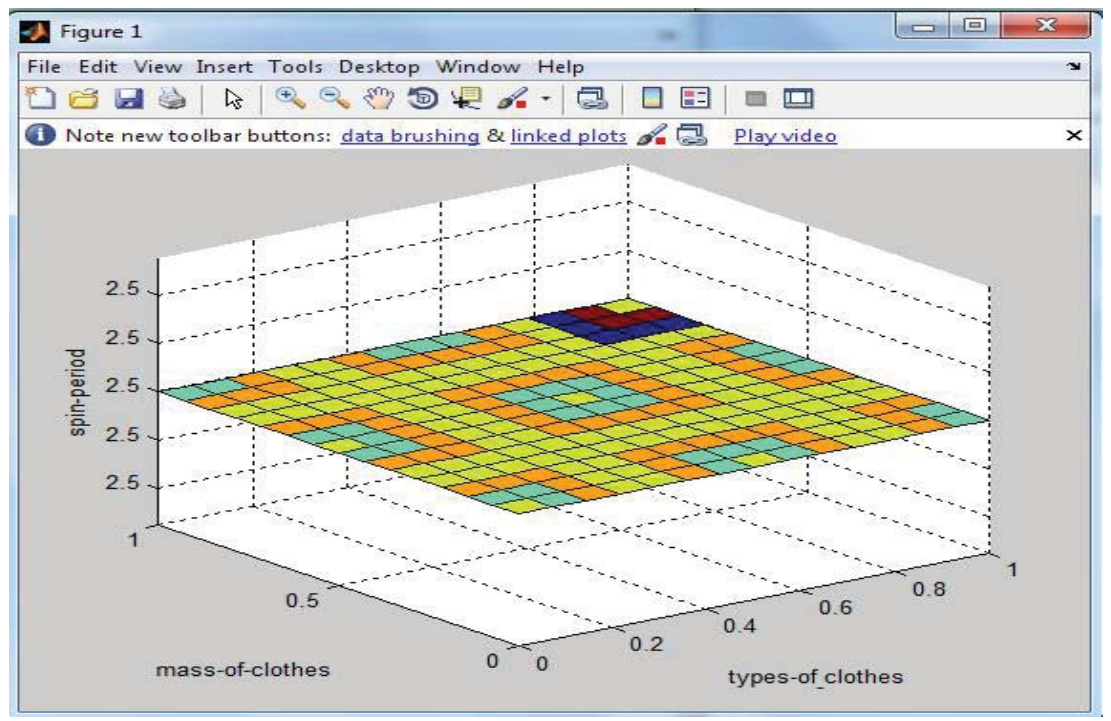

Figure. 10 Surface Viewer for Spin period

By the use of fuzzy logic control we have been able to obtain a wash time, rinse period and spin period for different type of dirt and different degree of dirt and different type of cloths. The conventional method required the human interruption to decide upon what should be the wash time for different cloths. In other words this situation analysis ability has been incorporated in the machine which makes the machine much more automatic and represents the decision taking power of the new arrangement.

Here the sensors sense the input values and using the above Model the inputs are fuzzyfied and then by using simple if-else rules and other simple fuzzy set operations the output fuzzy function is obtained and using the criteria the output value for wash time, rinse period and spin period is obtained.

The results (the above plot) shows the way the machine will response in different conditions. This is quite convincing and appropriate.

\section{CONCLUSION}

By the use of proposed fuzzy logic Controller, we have been able to obtain different Wash Time, Rinse Period, Spin Period (output Variable) for different Type of Dirt, Dirtiness of Clothes, Types of Clothes, Mass of Clothes and Temperature (Input Variable). This analysis also leads to saving in electrical energy and time for washing the clothes by using proposed Washing Machine. This proposed advance and automatic sensor system based Washing Machine depicts the advantage of Fuzzy Logic Controller in the conventional Washing Machine.

\section{REFERENCES}

[1] L.A. Zadeh, Fuzzy Sets, Information and Control, 338-353, (1965)

[2] Han H., Chun-Yi and Yury. S, Adaptive Control of a Class of Non-linear Systems with Non-Linearly Parameterized Fuzzy Approximation. IEEE Transactions on Fuzzy Systems, V0l.9, No.2, 315-323, (2001)

[3] Workman, M. Hardware requirement for Fuzzy Logic Control Systems. Lubbock, TX: Texas Tech University, (1996)

[4] George J. Kilr and Bo Yuan, Fuzzy Sets and Fuzzy Logic (India: PHI, 1995)

[5] Sonia Chhabra, VHDL Implementation of Fuzzy Control System, (2006)

[6] Dharamniwas, Aziz Ahmad, Varun Redhu and Umesh Gupta, Liquid Level Control by Using Fuzzy Logic Controller, International Journal of Advances in Engineering \& Technology, (July 2012). ISSN: 2231-1963.

[7] Ge Zhe-Xue, Sun Zhi-Qiang. Neural N/w Theory and the realization MATLAB (Beijing: Electronics industry publishing, 2007)

[8] Lohani P., and Hasan,S.R..Design of an Improved Controller Microchip For Washing Machine, $16^{\text {th }}$ Annual Electronics New Zealand Conference (pp. 20-26).Dunedin : Otago University (2009)

[9] Manish Aggarwal, Fuzzy Logic Controller for Washing Machine, IIT Kharagpur (2011). 